DOI: https://doi.org/10.47405/mjssh.v6i10.1128

\begin{tabular}{|c|c|}
\hline 5 & Malaysian Journal of Social Sciences and Humanities (MJSSH) \\
\hline Malaysian Journal of & Volume 6, Issue 10, October 2021 \\
\hline (MJ. SSH) & e-ISSN : 2504-8562 \\
\hline & $\begin{array}{l}\text { Journal home page: } \\
\text { www.msocialsciences.com }\end{array}$ \\
\hline
\end{tabular}

\title{
Eko Kritik Puisi Pilihan Malaysia dan Indonesia
}

\author{
Mohd. Saberi Muda1, Mas Rynna Wati Ahmad² \\ ${ }_{1}^{1}$ Muzium Negeri Terengganu, Terengganu, Malaysia \\ ${ }_{2}^{2} J a b a t a n$ Bahasa, Kesusasteraan dan Kebudayaan Melayu, Fakulti Sains Sosial dan Kemanusiaan, Universiti Kebangsaan \\ Malaysia (UKM), Bangi, Selangor, Malaysia
}

Correspondence: Mas Rynna Wati Ahmad (masrynna@ukm.edu.my)

\begin{abstract}
Abstrak
Suara sasterawan dalam isu alam sekitar menjadi satu tema yang tidak asing lagi dalam penulisan dunia sejagat. Alam sekitar yang menjadi sebahagian dari kehidupan ini menjadi sumber dalam proses pengkaryaan. Puisi-puisi hijau adalah antara karya yang muncul pada perkembangan dunia penulisan puisi di Malaysia dan Indonesia. Dua negara berjiran ini turut memiliki permasalahan yang hampir sama dalam isu alam sekitar. Justeru itu keprihatinan penyair dalam isu ekosistem ini diperlu dianalisis menerusi kajian eko kritik bagi merincikan lontaran pemikiran tersebut. Puisi-puisi tersebut seperti "Balada Terbunuhnya Beringin Tua di Pinggir Sebuah Bandar Raya" karya Usman Awang (1979), "Hari Terakhir Sebuah Hutan" karya Muhammad Haji Salleh (1989) dan "Debu dan Dendam Alam" karya Baha Zain (1997). Manakala dari Indonesia puisi-puisi yang serupa adalah "Membaca TandaTanda" oleh Taufik Ismail (1982), "Danau Toba" oleh Sitor Situmorang (1982) dan "Pandangan Senjakala" karya WS Rendra (1967). Periodisasi karya-karya yang mewakili era tahun 1960-an hingga 1990an ini memperlihatkan perjuangan yang berterusan dari penyair kedua-dua negara. Pendekatan eko kritik yang digunakan bagi menganalisis karya tersebut difokuskan kepada elemen ekologi, etika, bahasa dan kritikan sebagai kerangka kajian. Kajian yang melihat hubungan manusia dengan alam ini turut menyenaraikan manfaat alam pada seluruh kehidupan serta tanggapan atau perlakuan moral manusia terhadap alam. Etika dan perlakuan moral ini merupakan sebahagian dari tanggung jawab dalam sistem nilai sesebuah masyarakat. Manakala bahasa dan kritikan pula merupakan kaedah penyampaian penyair bagi perkongsian pemikiran dalam usaha melestarikan alam sekitar. Nostalgia, kehilangan serta protes dalam karya akan memperlihatkan kesan kerosakan alam sekitar yang memerlukan kepada pemuliharaan. Pemuliharaan khazanah warisan ini perlu ditangani dengan bijaksana demi kesejahteraan warga di masa akan datang.
\end{abstract}

Kata kunci: eko kritik, kelestarian alam, etika, nostalgia, khazanah warisan

\section{Ecocriticism in Selected Malaysian and Indonesian Poems}

\begin{abstract}
Environmental issues have been an uncommon theme among many writers as nature is important as their source of artistic inspirations. It is to be found that, some of the poets from Malaysia and Indonesia were keen to write on green poetries; poems that are associated with nature that reflect similar environmental issues in both countries. Therefore, reading these poems through the lens of Eco criticism would be deemed wise. For the purpose of this paper, poems from Malaysia such as "Balada Terbunuhnya Beringin Tua di Pinggir Sebuah Bandar Raya" by Usman Awang (1979), "Hari Terakhir
\end{abstract}


Sebuah Hutan" by Muhammad Haji Salleh (1989) and "Debu dan Dendam Alam" by Baha Zain (1997), will be studied along side with poems from Indonesia such as "Membaca Tanda-Tanda" by Taufik Ismail (1982), "Danau Toba" by Sitor Situmorang (1982) and "Pandangan Senjakala" by WS Rendra (1967). Selection of the poems were based on the specific periodization that these poems represented. This would reflect the poets long, and unending struggle to voice their concerns over the matter. Eco criticism will look at the ways in which the elements of ecology, ethics, and language suitable for the critical analyses. This study will not only highlight the importance of nature's contribution towards ecology, but also how the human values it through their ethics in achieving balance. The paper traces the importance of ethics which is part of the society's values in preserving the nature, while, the elements of language presented in the poems will prove further the ideas of environmental sustainability suggested. The protests and nostalgic elements in the poems symbolized the poets's cry for attention from people to work on more efforts to save the environment as it is a heritage for the future generation.

Keywords: eco crticism, sustainability, ethics, nostalgia, heritage

\section{Pengenalan}

Lingkungan persekitaran atau alam menyediakan pelbagai bahan bagi kesejahteraan dan kelestarian kehidupan. Interaksi antara manusia dan alam merupakan satu etika alamiah. Etika alamiah ini merujuk kepada tingkah laku manusia secara semula jadi atau bagaimana kaedah manusia berinteraksi dengan alam sekitar. Proses ini merupakan sebahagian dari sistem nilai yang diamalkan oleh sesebuah masyarakat dan sistem nilai ini berkait rapat dengan perlakuan moral.

Hakikat alam sebagai sebahagian dari kehidupan manusia ini dapat dilihat dari berbagai aspek. Para ilmuwan memanfaatkan alam untuk diteliti dan dimanfaatkan bagi kesejahteraan manusia. Dari sudut yang lain para orpotunis berusaha mengeksploitasi alam dengan teknologi atas nama pembangunan kadangkala mengabaikan isu kelestarian alam sehingga menimbulkan kerosakan sistem ekologi alam itu sendiri. Para seniman memandang alam sebagai sumber inspirasi dan renungan untuk diekspresikan dalam variasi medium seni yang pelbagai. Puisi, cerpen, novel, seni catan, filem dan lagu-lagu adalah antara medium yang menjadikan alam sebagai subjek dalam karya sama ada menvisualkan keindahan atau kerosakan. Isu-isu kerosakan alam ini sebahagiannya merupakan kritikan yang digolongkan sebagai eko kritik dalam dunia kesusasteraan sejagat.

Permasalahan alam sekitar itu menjadi bahan renungan pengarang untuk berkarya sehingga sastera mampu menjadi wadah membincangkan permasalahan alam sekitar yang dihadapi manusia sehinggakan wujudnya eko kritik bagi menilai karya itu. Maka jelaslah apa yang ingin disampaikan oleh para sarjana bahawa eko kritik ini lahir kerana adanya perbincangan mengenai masalah alam sekitar yang mana eko kritik ini merupakan kritikan sastera mengenai alam sekitar.

Dua buah buku hasil suntingan oleh Cheryll Glotfelty \& Harold Fromm iaitu The Ecocriticism Reader (1996) dan The Environmental Imagination (1996) oleh Lawrence Buell menjadi penanda aras dimana kritikan eko mula diperkatakan. Meskipun teori kritikan ini muncul agak lewat sekitar pertengahan 1990-an, namun istilah ecocriticism sebenarnya telah digunakan semenjak tahun 1970-an lagi. Tafsiran atau definisi eko kritik menurut Cheryll (1996),

\section{...ecocriticism is the study of the relationship between literature and the physical environment...eocritism takes an earth-centered approach to literary study.}

Bagi Glotfelty, kritikan eko adalah satu kritikan yang mengkaji hubungan antara sastera dan persekitaran fizikal. Hubungan ini boleh dijelaskan dengan melihat hubungan antara alam dan budaya. Budaya yang dimaksudkan ialah bahasa dan sastera. Hubungan ini bersifat timbal balik atau dua hala. Misalnya, Melalui bahasa, sastera membincangkan permasalahan yang berkaitan dengan alam sekitar. Manakala permasalahan alam sekitar menjadi habuan renungan pengarang untuk berkarya sehingga 
sastera mampu menjadi wadah membincangkan permasalahan alam sekitar yang dihadapi oleh manusia. Manakala pengkritik yang menggunakan kritikan ini bertindak sebagai seorang environmentalis, iaitu cenderung untuk prihatin kepada permasalahan alam sekitar secara bersungguh-sungguh sebagaimana yang dinyatakan oleh Morton (2007)

\section{“..Enviromentalism is aset of cultural and political responses to a crisis in humans'relationship with their surroundings"}

Alam sekitar merupakan satu isu sejagat yang mempunyai pelbagai kaedah pendekatan dalam menangani masaalah tersebut. Sebagai negara berjiran, Malaysia dan Indonesia turun mempunyai pengalaman bersama dalam menyelesaikan isu tersebut. Sasterawan serta seniman kedua-dua negara turut menyuarakan pandangan, kritikan, ulasan serta cadangan tersendiri melalui medium dan genre masing-masing. Namun perbincangan khusus kepada eko kritik terhadap karya-karya tersebut agak kurang mendapat perhatian kecuali hanya beberapa orang sarjana yang melihat kepentingan karya-karya tersebut. Sebagai contoh Sohaimi (2013), yang menyatakan bahawa kritikan eko ini merupakan kritikan sastera alam sekitar dan kritikan ini wujud kerana adanya kesusasteraan alam sekitar yang terikat dengan ekologi budaya. Seterusnya, Sohaimi (2014) juga ada menyatakan bahawa karya kesusasteraan mempunyai kritikan eko (ecocriticism), dimana ia berkait rapat dengan konsep menghijaukan teks yang melibatkan pengetahuan tentang ekologi iaitu satu cabang biologi yang memperkatakan tentang hubungan organisma hidup dengan persekitarannya (2014, xxxii). Manakala Mohd Saberi (2015) turut mengulas puisi-puisi Marzuki Ali melalui pendekatan eko krtik yang memperlihatkan stamina Marzuki Ali dalam menyuarakan isu-isu alam sekitar melalui beberapa kumpulan puisinya diterbitkan bermula 1980-an sehingga 2018.

Manakala di Indonesia, sarjana-sarjana tempatan turut mengulas dalam tafsiran serta manfaat eko kritik. Harsono (Widianti 2017, 2) misalnya melihat eko kritik memiliki paradigma dasar bahwa setiap objek dapat dilihat dalam jaringan ekologis dan ekologi dapat dijadikan alat bantu dalam pendekatan kritik. Eko kritik merupakan kajian hubungan antara sastera dan lingkungan fizikal iaitu satu kajian kesusasteraan yang berpusat pada dunia (earth-centered). Manakala Kaswadi (2015) mengulas bahawa eko kritik disebut sebagai kajian hijau atau sastera hijau yang antara lain membicarakan perihal cara alam diwakili oleh puisi, cara menjelaskan ciri-ciri genre kesusasteraan alam sekitar serta cara krisis alam sekitar memasuki kesusasteraan kontemporari.

Bagi menyemarakkan lagi bidang eko kritik, kajian ini akan berusaha menganalisis 6 buah puisi dari penyair Malaysia dan Indonesia khusus dengan pendekatan elemen-elemen yang menjadi teras dalam eko kritik. Puisi-puisi tersebut adalah "Balada Terbunuhnya Beringin Tua di Pinggir Sebuah Bandar Raya" karya Usman Awang (1979), "Hari Terakhir Sebuah Hutan" karya Muhammad Haji Salleh (1989) dan "Debu dan Dendam Alam" karya Baha Zain (1997). Manakala dari Indonesia puisi-puisi yang dipilih adalah "Membaca Tanda-Tanda" oleh Taufik Ismail (1982), "Danau Toba" oleh Sitor Situmorang (1982) dan "Pandangan Senjakala" karya WS Rendra (1967). Periodisasi karya-karya ini yang mewakili era 1960-an sehingga 1990-an ini memperlihatkan keprihatinan penyair-penyair ini menyuarakan isu alam sekitar secara berterusan hatta sehingga ke dekad ini.

Pendekatan analisis puisi-puisi ini adalah berdasarkan pada perinsip-perinsip yang digagaskan oleh William (1996) yang mendasari kritikan eko, iaitu ekologi, etika, bahasa dan kritikan. Keempat-empat prinsip ini saling berhubungan;

I try to work within a set of informed, responsible principles, derived from four disiplines; ecology, ethics, language and criticism. To me they offer combination of theory and method that explore environmental literature. As an interdisciplinary science, ecology describes th relation between nature and culture... 


\title{
Pendekatan Ekologi
}

Mengikut Howarth (1996:71), ... ecology describes the relations between nature and culture. Interaksi alam semula jadi mencakupi keseluruhan persekitaran bukan sahaja berhubungan dengan manusia tetapi juga hidupan lain yang lain yang saling melengkapi eko sistem setempat. Penelitian terhadap eko sistem wujud hasil daripada saling tindakan antara komponen-komponen hidup dan bukan hidup merupakan satu salah satu cabang ekologi yang disebut sebagai ekologi manusia. Sebagai contoh, kegiatan tebus guna tanah untuk pembangunan yang tidak terkawal akan memberi kesan kepada alam sekitar seperti pencemaran sungai, banjir lumpur dan bahang panas yang meningkat yang sudah tentu menggugat kesejahteraan kehidupan.

Puisi ekologi turut disebut puisi alam atau puisi hijau mengangkat tema mengenai kondisi lingkungan atau alam itu sendiri. Melalui penciptaan karya puisi yang eksplisit dan implisit, seorang penyair ingin 'mengingatkan' pembaca tentang kepentingan melestarikan dan melindungi lingkungan sebagai satu rangkaian ekosistem. Dengan kata lain, matlamat penyair adalah memberikan motivasi serta menanam kesedaran tentang kepentingan khazanah alam yang menjadi sebahagian dari kehidupan masyarakat. Manakala dalam konteks puisi, ianya mengimplikasikan dua fungsi, iaitu dulce dan utile (indah dan berguna) (Wellek \& Warren:1956).

Menerusi puisi "Balada Terbunuhnya Beringin Tua di Pinggir Sebuah Bandaraya" pembaca divisualkan dengan landskap sepohon Beringin dengan persekitarannya. Penyair menyenaraikan landskap persekitaran yang melengkapi satu sistem ekologi dimana kebergantungan hidupan antara satu-sama lain dalam satu kitaran yang sempurna. Ibu kota, matahari, bumi, keluarga burung-burung, kupu-kupu dan anak-anak memanfaatkan kewujudan Beringin Tua tersebut.
Beringin tua di pinggir sebuah bandar raya
di sebuah ibu kota yang setengah muda
ratusan tahun usianya berdiri
menadah matari memayungi bumi
burung-burung berterbangan menyanyi
di sini rumah mereka, di sini keluarga bahagia
kupu-kupu berkejaran dalam senda guraunya
anak-anak bermain di keteduhan perdunya.
...
(Puisi-Puisi Pilihan Usman Awang 1987, 31)

Melalui puisi "Debu dan Dendam Alam", Baha Zain memberi peringatan tentang ancaman pencemaran yang berlaku kesan dari ganggu gugat alam sekitar terutama dalam isu pembakaran hutan yang mengakibatkan fenomena jerebu yang melanda tanah air saban tahun dahulu.

\author{
jangan buka daun jendela \\ dan tutup pintumu \\ mereka mengendap di perkarangan \\ setelah memerun hutan belantara \\ menewaskan binatang dan serangga \\ sekarang tiba giliran \\ mencekik kita yang terperangkap di kota dan di desa.
}

( Esei dan Puisi Baha Zain 2014,165)

Penggunaan kosa kata 'mereka mengendap di perkarangan/setelah memerun hutan belantara/menewaskan binatang dan serangga merupakan frasa mudah difahami secara langsung berhubung dengan turutan peristiwa yang berlaku. Beliau turun menyenaraikan elemen alam sekitar yang melengkapi ekologi setempat seperti hutan belantara, binatang serta serangga. 
Isu pengurusan alam sekitar di Indonesia turut dikongsi bersama melalui buku Pengurusan Alam Sekitar di Malaysia dan Indonesia sebagai suatu langkah awal untuk mengetengahkan isu, masalah dan langkah-langkah pengurusan alam sekitar di dua buah negara jiran yang mempunyai kedudukan geografi yang hampir serupa. Kehampiran tersebut menjadikan kedua-dua buah negara juga mengalami iklim yang sama dan segala isu dan masalah yang dihadapi berkaitan alam sekitar juga umumnya dapat mengaplikasikan langkah yang lebih kurang serupa untuk menanganinya. Tambahan lagi sejak beberapa dekad yang lalu pengurusan alam sekitar telah lebih terpandu, terutamanya apabila negara-negara dunia menyedari kepentingan alam sekitar dan mengaplikasikan konsep pembangunan mapan bagi memastikan peningkatan kualiti hidup rakyatnya ( Jamaluddin, 2013).

Melalui puisi "Membaca Tanda-Tanda" Taufiq Ismail seorang penyair Indonesia memerihalkan kesan kerosakan alam seperti pencemaran udara, sumber air, burung-burung serta hutan. Taufiq Ismail turut menyenaraikan 'kehilangan' yang disusun secara berulang dengan rima berangkai (chain rhyme) menggambarkan kitaran yang berkait antara satu sama lain. Kemusnahan atau kehilangan sesuatu unsur/hidupan akan memberi kesan langsung pada unsur/kehidupan lain. Melalui puisi Membaca Tanda-tanda (1982), penyair mengajak pembaca untuk melihat gejala-gejala alam yang terjadi di Indonesia. Hal tersebut mempunyai makna bahawa puisi tersebut telah merepresentasikan krisis ekologi di Indonesia (Nurul, 2018)

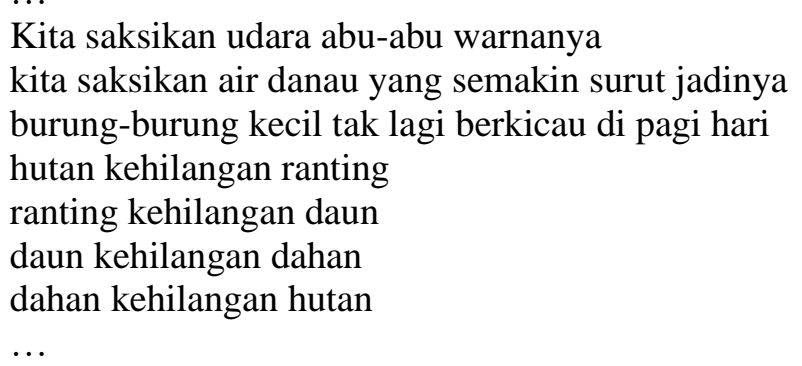

(Puisi-Puisi Langit :1990: 3)

Perubahan alam digambarkan penyair melalui hal yang kecil seperti ranting, daun dan dahan sehingga hal yang besar seperti hutan. Perubahan alam yang membuat penyair merasa hilang keaslian dan kenyamanan alam (Arianty, 2020). Manakala penyair mapan Indonesia Sitor Situmorang mengimbau nostalgia keindahan landskap dan sosiobudaya yang melengkapi ekologi tanah kelahiran dengan ungkapan 'rindu' pada masa lalu melalui puisi "Danau Toba". Kerinduan pada tanah Danau Toba yang penuh dengan citra tradisi dan alam semula jadi yang segar disenaraikannya secara terperinci melalui bait-bait berikut;

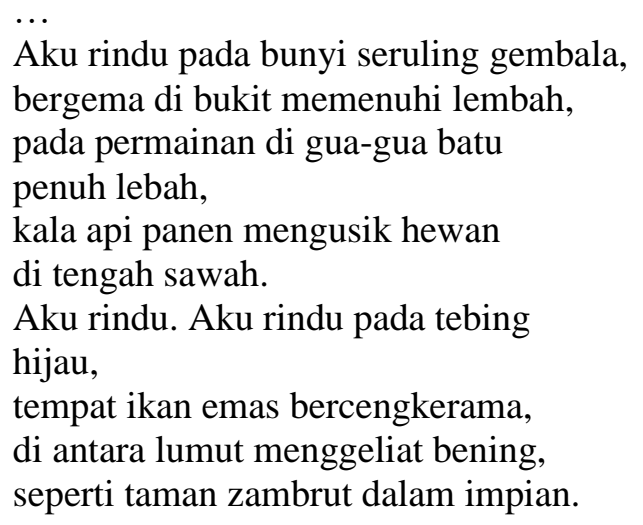

(Angin Danau. 1982, 16-19)

Nostalgia dan kerinduan merupakan dua frasa yang menjadi tunjang naratif puisi di atas bilamana penyair menggambarkan lingkungan persekitaran dengan kepelbagaian budaya dan kehidupan yang saling melengkapi antara satu sama lain sehingga menimbulkan kesan 'rindu' yang mendalam pada suasana tersebut. 
Dengan perspektif yang berbeza, WS Rendra menvisual kesan dramatik yang 'brutal' dari pembangunan yang tidak terkawal. 'Kayu-kayu hutan yang hangus diredakan oleh senja yang basah' memperlihatkan secara jelas tentang kebakaran hutan manakala 'kelelawar raksasa datang dari langit kelabu tua' sebagai perlambangan golongan oportunis yang berleluasa merosakkan alam sekitar.

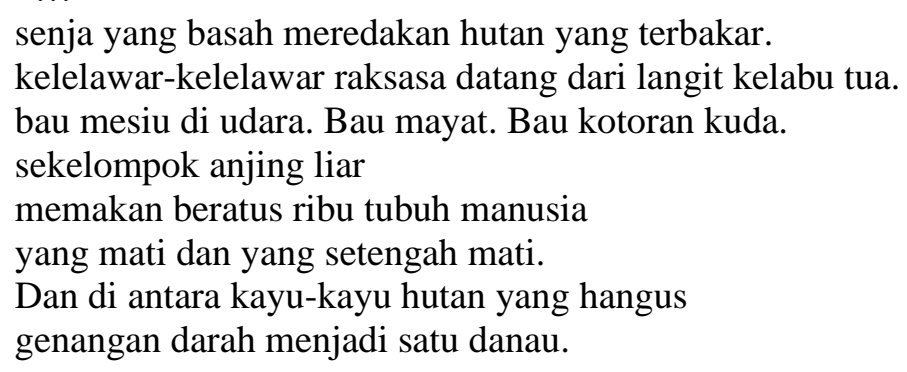

(Balada Si Burung Merak. 2016, 196 )

Penyair mengungkapkan selain kemuraman juga renungan tentang perilaku manusia yang sering menghancurkan alam untuk ambisi mereka dalam menyelesaikan masalah dengan kekerasan dan peperangan. Tergambar dari puisinya yang menggunakan diksi yang tajam juga mendalam membuat puisi Rendra berkesan gagah dan memberi keyakinan (Ekarini, 2016).

\section{Pendekatan Etika}

Diksi etika merujuk kepada bagaimana tingkah laku, perbuatan atau kaedah manusia berinteraksi dengan alam sekitar. Etika antara lain bermaksud sistem nilai atau perlakuan moral yang diamalkan oleh sesebuah masyarakat. Etika turut berfungsi untuk "offer ways to mediate historical social conflicts". Dalam konteks kritikan eko, etika dirincikan dengan konsep etika ekologikal. Etika ekologikal pula difahami dengan merujuk kepada dua pergerakan ekologikal yang dikenali sebagai deep ecological movement dan shallow ecological movement. Mengikut Evernden (1996:102), deep ecological movement ialah:

The 'deep ecological movement', the one that concerns itself with the underlying roots of the environment crisis rather than simply its physical manifestation, demands the involvement of the arts and humanities.

Menerusi deep ecological menurut Evernden, ianya merupakan manifestasi keprihatinan kepada permasalahan alam sekitar dan mengajak masyarakat termasuk budayawan, sasterawan dan humanis memainkan peranan ke arah kelestarian alam. Etika deep ecology ternyata sangat positif kerana sikap dan tindakannya mesra alam demi kesejahteraan manusia sekaligus memerikan setiap unsur alam sekitar itu berhubungan antara satu sama lain. Seoerui bait puisi di bawah,

Ada sesuatu yang rasanya mulai lepas dari tangan

dan meluncur lewat sela-sela jari kita

Ada sesuatu yang mulanya tak begitu jelas

Tapi kini kita mulai merindukannya

Beri kami kearifan membaca tanda-tanda

Karena ada sesuatu yang rasanya mulai lepas dari tangan

dan meluncur lewat sela-sela jari kita

Karena ada sesuatu yang mulanya tak begitu jelas

tapi kini kami mulai merindukannya. 
Taufik Ismail memulakan bait puisi "Membaca Tanda-Tanda" dengan kegusaran dan pertanyaan berbentuk introspektif tentang kekeliruan terhadap tanda-tanda alamiah yang berlaku di sekelilingnya seperti perubahan fizikal tentang alam sekitar serta bencana dan malapetaka yang menimpa. Bait akhir puisi turut mengulangi frasa yang sama sebagai satu penegasan maksud yang ingin disampaikan pada pembaca. Penegasan ini bertujuan mengajak masyarakat untuk memahami tanggung jawab sebagai manusia yang diamanahkan untuk menjaga kesejahteraan alam.

Kalimat /bisakah kita membaca tanda-tanda?/, dan terutama kalimat /beri kami kearifan membaca tanda-tanda/ merupakan doa manusia kepada tuhan, bermakna kembalinya keinginan manusia untuk melihat tanda-tanda alam. Dengan mengetahui tanda-tanda yang ada di alam, apakah alam sedang terluka, atau apakah memerlukan perhatian manusia, maka manusia akan dapat hidup harmonis dengan alam. Hal ini adalah bagian dari sikap kepedulian dan kasih sayang manusia terhadap alam (Arianty, 2020)

Manakala pergerakan yang berasaskan kepada shallow ecology nyata berlawanan dengan deep ecology. Etika ekologikal yang berasaskan shallow ecology mempunyai sikap dan tindakan yang mengarah kepada memusnahkan alam sekitar sehingga menimbulkan krisis yang membawa musibah kepada kesejahteraan manusia. Etika ini ada kaitannya dengan pemikiran kapitalisme yang hanya mementingkan peribadi dan material di mana golongan ini melihat alam sebagai sumber atau lubuk yang memberikan pulangan material yang luar biasa.

Etika ekologikal ini bersifat negatif dan demi untuk pulangan material, kekejaman serta kezaliman terpaksa dilakukan;

Tiba-tiba pagi yang hitam itu datang

gergasi teknologi menyerangnya

dengan kejam membenamkan gigi-gigi besi

sehingga terdengarlah jeritan ngeri

suara Beringin rebah ke bumi.

$\ldots$

Namaku Beringin pohon tua yang terbuang

dimusuhi oleh rancangan bernama Pembangunan.

(Puisi-Puisi Pilihan Usman Awang 1987, 31)

"Gergaji teknologi", adalah satu metafora yang cukup tepat bagi menjelaskan kerakusan serta kekejaman manusia terhadap alam semula jadi. Simbol ini kemudiannya didramatikkan dengan adeganadegan berikut;

dengan kejam membenamkan gigi-gigi besi

sehingga terdengarlah jeritan ngeri

suara Beringin rebah ke bumi.

Menerusi bait puisi ini Usman Awang berjaya mengatur imaginasi pembaca dengan adegan-adegan yang cinemascopic sehingga membangkitkan simpati dan aksi penentangan terhadap kekejaman. Suhaimi Abd. Aziz (2014 :383) melabelkan golongan shallow ecology ini sebagai etika ekologi yang 'hodoh' yang diperjelaskan lagi dalam bait puisi berikut;

hikayat penuh hutan

ditamatkan oleh sepasukan lori yang bertayarkan angkuh

sekumpulan pemotong gajian yang memakai kesedihan di matanya.

dan seorang pembalak gemuk

yang berdiri di gurun merah kontang - dunia akan datang.

(Sebuah Unggun di Tepi Danau 1996, 3 ) 
DOI: https://doi.org/10.47405/mjssh.v6i10.1128

Muhammad Haji Salleh mengakhiri bait puisi ini dengan satu visual dimana 'pembalak yang gemuk' representasi golongan shallow ecology yang haloba yang 'berdiri di gurun merah kontang' sebagai lambang alam dan persekitaran akan datang. 'Gurun merah kontang' adalah satu frasa yang terjadi akibat kerakusan golongan oportunis dalam mengeksploitasi sumber alam.

Melalui puisi 'Debu dan Dendam Alam' pula Baha Zain memperincikan sikap dan karakter golongan orpotunis yang bertunjang kepada kekuasaan sehingga melenyapkan pertimbangan akal dan kasih sayang. Diksi ' jari-jari mereka panas berbara'/bersalut debu dan dosa' memperihalkan tentang tangantangan yang melakukan kegiatan kerosakan alam yang diibaratkan 'membakar sekalian yang hijau'.

mereka sudah hilang bicara

hilang pertimbangan dan kasih sayang

kekayaan itu adalah segala-galanya

kekuasaan ada di belakangnya

jari jari mereka panas berbara

bersalut debu dan dosa

membakar sekalian yang menghijau

(Esei dan Puisi Baha Zain 1997, 165)

WS Rendra menggambarkan imaginasi kreatifnya tentang fenomena kerosakan alam sebagai amaran kepada golongan yang melakukan kerosakan alam dengan figura-figura 'brutal' seperti rambut mayatmayat, permukaan danau darah dan syahwat para malaikat dan kelelawar.

Angin yang sejuk bertiup sepoi-sepoi basa

menggerakkan rambut mayat-mayat

membuat lingkaran-lingkaran di permukaan danau darah

dan menggairahkan syahwat para malaekat dan kelelawar.

Ya, saudara-saudaraku,

aku tahu inilah pemandangan yang memuaskan hatimu

kerna begitu asyik kau telah menciptakannya.

(Balada Si Burung Merak, 2016)

Penyair pada akhir puisi melontarkan pertanyaan secara ironi kepada sipelaku kerosakan tersebut nama ganti nama bersopan iaitu 'saudara-saudaraku' yang menyukai pemandangan akibat dari perbuatan tangan-tangan mereka sendiri.

\section{Pendekatan Bahasa dan Kritikan}

Bahasa dan kritikan merupakan dua elemen yang saling berhubungan. Kritikan sudah tentu menggunakan medium bahasa yang disampaikan secara lisan atau tulisan. Howarth $(1996,71)$ berpandangan bahawa bahasa dan kritikan adalah dua daripada prinsip-prinsip dalam kritikan eko. Kedua-dua prinsip ini dijelaskannya di dalam petikan berikut:

"Language theory examines how words represent human and nonhuman life. Criticism judges the quality and integrity of works and promotes their dissemination"

Bagi Howarth, bahasa adalah alat yang digunakan oleh pengarang untuk mengungkap tentang kehidupan manusia dan bukan manusia. Dalam konteks kritikan eko ianya berkait langsung dengan persoalan-persoalan ekologi dan etika ekologikal. Howarth menyimpulkan bahawa bahasa mampu menjalinkan alam sekitar dan budaya atau lebih tepat antara ekologi dan etika ekologikal. 
Penguasaan bahasa figuratif atau kiasan yang baik dan sempurna menjadikan karya puisi moden kaya dengan makna. Penyair menggunakan konsep licentia-poetica atau lesen dan kebenaran untuk menggunakan manipulasi bahasa bagi mengungkapkan makna sebanyak mungkin.

Selamat tinggal, selamat tinggal wahai awan

Selamat tinggal matari selamat tinggal bulan

Selamat tinggal kupu-kupu sayang

Selamat tinggal wahai burung-burung bersarang

Selamat tinggal anak-anak bermain riang.

(Puisi-Puisi Pilihan Usman Awang. 1987, 31)

Melalui puisi "Balada Terbunuhnya Beringin Tua di Pinggir Sebuah Bandaraya" ini penyair memasukkan unsur pengulangan atau anafora. Pengulangan kata pada awal baris secara berturutan ini menimbulkan kesan estetik tersendiri. Konkordans telah digunakan untuk melihat kekerapan penggunaan perkataan 'selamat tinggal' yang terdapat dalam puisi. Terdapat sebanyak tujuh kali perkataan 'selamat tinggal' telah dapat dikesan pengulangannya sama ada dalam baris yang sama ataupun yang berbeza.

Pengulangan-pengulangan ini melihatkan penegasan serta menimbulkan kesan emotif tersendiri kepada para pembaca. Gaya bahasa juga adalah bahasa indah yang digunakan untuk meningkatkan kesan mendalam di hati pembaca dengan jalan memperkenalkan serta membandingkan sesuatu benda atau hal tertentu dengan benda lain yang lebih umum.

Teknik repitisi atau pengulangan dalam puisi "Hari Terakhir sebuah Hutan" karya Muhammad Haji Salleh juga memberikan impak keindahan dalam bahasa. Diksi 'rebah' yang diulang-ulang sebanyak 10 kali bagi memperihalkan 10 spesies pokok-pokok hutan yang dieksploitasi demi kepentingan dan keuntungan material golongan tertentu. Pengulangan ini juga memberikan imaginasi yang berterusan secara langsung kepada pembaca sehingga menjadikan diksi 'rebah' melekat dalam minda pembaca,

$$
\begin{aligned}
& \text { rebah cengal } \\
& \text { rebah meranti } \\
& \text { rebah merbau } \\
& \text { rebah pulai } \\
& \text { rebah seraya } \\
& \text { rebah nyatuh } \\
& \text { rebah resak } \\
& \text { rebah halban } \\
& \text { rebah nibung } \\
& \text { rebah rotan }
\end{aligned}
$$

(Sebuah Unggun di Tepi Danau. 1996, 92)

Manakala, Taufik Ismail juga turut menggunakan kaedah repitisi timbal balik dalam puisi "Membaca Tanda-Tanda" seperti di bawah;

$$
\begin{aligned}
& \text { hutan kehilangan ranting } \\
& \text { ranting kehilangan daun } \\
& \text { daun kehilangan dahan } \\
& \text { dahan kehilangan hutan }
\end{aligned}
$$

\section{( Membaca Tanda-Tanda 1982, 3)}

Teknik repitisi timbal ini bagi memperlihatkan hubungan timbal balik yang ada di alam atau ekosistem. Segala sesuatu yang ada di alam saling berkaitan termasuk manusia dan makhluk hidup lain saling 
berkaitan dengan alam. Taufik turut memberi kefahaman tentang fenomena biasa terjadi dalam bait kedua iaitu ketika gunung api meletus dan mengeluarkan abu, abu menjadi batu, batu menjadikan lindu atau gempa. Gempa akan membuat tanah menjadi longsor, longsor menyebabkan air dari daerah tinggi mengalir dan membawa banjir, dan akhirnya manusia menjadi mangsa yang berkemungkinan hasil tingkah laku manusia itu sendiri.

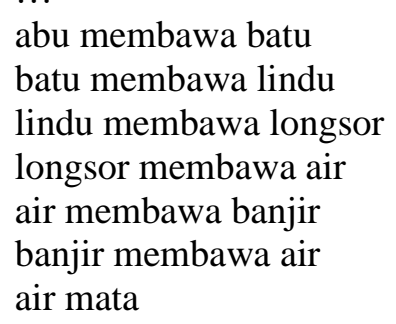

(Membaca Tanda-Tanda 1982, 3)

\section{Kesimpulan}

Secara dasarnya hubungan alam dengan kesusasteraan yang menjadi teras dalam eko kritik dapat dirincikan menerusi pendekatan ekologi, etika dan bahasa dan kritikan. Alam telah menyajikan bahan mentah bagi kelahiran karya sastera. Ini ditunjukkan oleh sejumlah besar penulis terutama penyair, yang mewakili alam dalam karya-karyanya (puisi) dalam bentuk diksi, seperti; hutan, laut, pohon, gunung, binatang, dan lain sebagainya. Sastera masa lalu adalah cermin dari masa lalu, sedangkan sastera masa kini adalah cermin masa kini. Karena itu, sastra sebagai inspirasi erat kaitannya dengan alam, manakala alam memerlukan sastera sebagai medium pelestariannya.

Sebagai rumusan, menerusi pendekatan ekologi, karya-karya penyair ini memperihalkan kesan-kesan kemusnahan eko sistem sekali gus menyuarakan tentang kehilangan, kerinduan serta nostalgia masa lalu yang sukar dikembalikan. Penyair melontarkan peri pentingnya menjaga kesejahteraan alam sekitar sekali gus menyuntik motivasi tentang tanggung jawab bersama demi kelestarian alam yang konsisten.

\section{Rujukan}

Arianty Visiaty. (2020). Ekosistem dalam Puisi Membaca Tanda-Tanda Karya Taufiq Ismail Sebuah Kajian Etis Ekokritik. Jurnal Al-Azhar Indonesia Seri Humaniora, 5(4), 182-188

Ekarini Saraswati. (2016). Inspirasi Alam Dalam Puisi-Puisi Karya Penyair Indonesia. Proceeding Himpunan Sarjana Kesusastraan Indonesia, 451-456

Glotfelt, C, \& Fromn, H. (1996). The Ecocriticisme Readers: Landmark in Literary Ecology Georgia: University of Georgia Press.

Harsono, Siswo. (2008). Ekokritik: Kritik Sastra Berwawasan Lingkungan. Kajian Sastra. Semarang: Universitas Diponegoro, 32, 1.

Howarth, W. (1966). Some Principles of Ecocriticism. The Ecocriticism Reader, disunting oleh Glotfelty, Cheryll\& Harold, Fromm. Athens and London: The University of Georgia Press.

Ismail Taufiq. (1990). Puisi-Puisi Langit. Jakarta:Yayasan Ananda

Jamaluddin Md. Jahi. Et al. (2013). Pengurusan Alam Sekitar di Malaysia dan Indonesia. Bangi: Institut Alam dan Tamadun Melayu (ATMA) Universiti Kebangsaan Malaysia.

Kaswadi. (2015). Paradigma Ekologi dalam Kajian Sastera. Jurnal Paramasastra, 2(2).

Maria L.A Sumaryati, \& Muhammad Nasar Helmi. (2019). Puisi-Puisi Langit By Taufiq Ismail: A Literary Ecology Study. The 28thnInterntional Confrence on Literature (IcoL) XXVIII. July 1113, 2019, Banda Acheh, Indonesia.

Mohamad Saleeh Rahamad (2016). Balada Si Burung Merak Puisi-Puisi Lengkap W.S.Rendra. Kuala Lumpur: Institut Terjemahan dan Buku Negara 
Mohd Saberi Muda \& Mas Rynna Wati Ahmad (2019). Eko-Kritik dalam Puisi Melayu dlm Akademika 89, 29-39.

Muhammad Haji Salleh. (1996). Hari Terakhir Sebuah Hutan. Kuala Lumpur: Dewan Bahasa dan Pustaka.

Nurul Setyorini. (2018). Representasi Krisis Ekologi Di Indonesia Puisi Membaca Tanda-Tanda Dan Menengadah Ke Atas Merenungi Ozon Yang Tak Nampak Karya Taufik Ismail. Jurnal Bahtera 05(9).

Sitor Situmorang. (1982) Angin Danau. Penerbit Sinar Harapan, Jakarta.

Sohaimi Abdul Aziz. (2014). Keprihatinan Usman Awang dalam melestarikan alam sekitar. Dlm. Dahsyatnya Kesusasteraan Memerihalkan Kehidupan, disunting oleh Sohaimi Abdul Aziz. Pulau Pinang: Universiti Sains Malaysia.

Sohaimi Abdul Aziz. (2014). Krisis Alam Sekitar dalam Puisi: Satu Kajian Hijau. Kuala Lumpur: Dewan Bahasa dan Pustaka.

Sohaimi Abdul Aziz. (2017). Pembelaan Terhadap Alam Sekitar dalam Puisi-Puisi Pilihan Usman Awang. Pulau Pinang: Penerbit Universiti Sains Malaysia.

Usman Awang. (1987). Balada Terbunuhnya Beringin Tua di Pinggir Sebuah Bandaraya. Kuala Lumpur: Dewan Bahasa dan Pustaka.

Wellek, R., \& Warren A. (1956). Theory of Litarature. 3rd ed. New York: Harcourt, Brace \& World. 